\title{
As Conferências Nacionais de Saúde e a política de saúde mental para a infância
}

\section{The National Health Conferences and the mental health policy for children}

\section{Las Conferencias Nacionales de Salud y la política de salud mental para la niñes}

\section{Clariana Morais Tinôco Cabral*}

Universidade Federal do Rio Grande do Norte - UFRN, Natal, Rio Grande do Norte, Brasil

\section{Rosângela Francischini**}

Universidade Federal do Rio Grande do Norte - UFRN, Natal, Rio Grande do Norte, Brasil

\begin{abstract}
RESUMO
As políticas nacionais de saúde mental para a infância no Brasil constituemse em uma tessitura complexa, ainda pouco explorada enquanto lócus de investigação, reflexão e crítica. Desta feita, compreender o percurso histórico pelo qual caminhou a saúde mental para a infância e juventude nesse país torna-se, também neste trabalho, um desafio a ser assumido. As Conferências Nacionais de Saúde (CNS) são tomadas como base referencial no presente trabalho, em virtude de seu pioneirismo, ao tornar as políticas brasileiras em saúde ações sistematizadas e organizadas em favor da efetivação de uma república democrática. A partir da análise dos relatórios produzidos com a realização das 14 CNS, pôde-se vislumbrar um panorama histórico mais fiel com relação à lógica proposta para atendimento das demandas em saúde mental infantil, ou o vácuo existente quanto à problematização e, consequentemente, à efetivação de ações que contemplem o seu seguimento.
\end{abstract}

Palavras-chave: infância, saúde mental, Conferências Nacionais de Saúde.

\section{ABSTRACT}

The national mental health policies addressed to young people in Brazil constitute a complex system, which is still little explored as a locus of research, consideration and criticism. Thus, understanding the historical background of the mental health for children and young people in this country becomes a challenge that must also be undertaken in this paper. The National Health Conferences (NHCs) are the basic parameter in this article due to their pioneering in transforming Brazilian health policies into systematic and organized initiatives in favor of a democratic republic. Based on the examination of the reports generated by the holding of the $14 \mathrm{NHCs}$, it was possible to envisage a more faithful historical panorama related to proposed conceptions to meet demands on child mental health, or the 
ongoing vacuum regarding the problematization, and, by consequence, to have an overview of the actions that must be taken in order to contemplate its effective promotion.

Keywords: young, mental health, National Health Conferences.

\section{RESUMEN}

Las políticas nacionales de salud mental para la niñez en Brasil se componen en una organización compleja, todavía poco explorada en cuanto lócus de investigación, reflexión y crítica. Después de realizada, comprender la ruta histórica por la cual se dirigió la salud mental para la infancia y juventud en este país se hace, también, en este trabajo, un reto a ser asumido. Las Conferencias Nacionales de Salud (CNS) conforman la base referencial en el presente trabajo debido a su importancia, al hacer las políticas brasileñas en salud acciones sistematizadas y organizadas en favor de efectuar una república democrática. A partir de la análisis de los informes producidos con la realización de los 14 CNS, se puede vislumbrar un panorama histórico más confiable con respecto a la justificación propuesta para el atendimiento de las demandas en salud mental infantil, o la falta de interés existente en cuanto al cuestionamiento y, por consecuencia, a la realización de acciones que recompensan la continuidad.

Palabras-clave: niñez, salud mental, Conferencias Nacionales de Salud.

\section{Introdução}

A criança, para a história do ocidente, por muito tempo carregou as marcas de coadjuvante, vindo a tomar evidência enquanto sujeito com características próprias no século XIX (Ariès, 1978). Todavia, o interesse social e científico para com a categoria infância não considerava todos os determinantes implicados na sua configuração, como, por exemplo, gênero, raça, etnia, classe social, religião, singularidades no que diz respeito a algum tipo de necessidade especial, dentre outros.

Tragicamente negligenciadas, as crianças "alienadas", as crianças "anormais", sofreram, em silêncio, as mais dolorosas e questionáveis práticas de intervenção sobre elas, sob a prerrogativa da ordem social e da proteção, sendo esta última distinta da proteção a que se remetem os documentos mais recentes que buscam resgatar a dignidade da pessoa da criança enquanto sujeito de direitos, como é o exemplo da Convenção Internacional sobre os Direitos das Crianças, de 1989 (Rosemberg \& Mariano, 2010). A proteção, naquele primeiro momento, estava ligada às situações de excepcionalidade, mais precisamente de desvio da norma. Proteger correspondia a salvar, salvar a criança era manter a salvo a sociedade dos possíveis danos que estas poderiam vir a causar à coletividade.

A força das marcas históricas expressa o caminho trilhado e o panorama atual das políticas em Saúde Mental para crianças, o seu início tardio, os vários momentos de vácuo e negligência. 
O que se conhece sobre a assistência em saúde mental infantil é recente se comparado com a jornada percorrida pela política de saúde mental para o adulto, por exemplo. Somente no século XXI são materializadas as reais propostas de atendimento ao grupo em questão, inserindo a criança, de forma efetiva, politizada e nas bases da Doutrina da Proteção Integral e da Universalidade da assistência em saúde (Couto \& Delgado, 2015).

As políticas nacionais de saúde mental para a infância no Brasil constituem-se em uma tessitura complexa, ainda pouco explorada enquanto lócus de investigação, reflexão e crítica. Desta feita, compreender o percurso histórico pelo qual caminhou a saúde mental para a infância no Brasil torna-se um desafio a ser assumido.

Os relatórios produzidos a partir da realização das Conferências Nacionais de Saúde (CNS) foram utilizados como marco histórico de referência na busca pela definição clara do cenário brasileiro de políticas em saúde mental para a infância, tendo em vista o pioneirismo destes eventos ao tornar as políticas de saúde no Brasil ações sistematizadas e organizadas em favor da efetivação de uma república democrática ${ }^{1}$.

Os debates promovidos com a realização desses eventos suscitaram outros espaços de debates como os articulados pelas Conferências Nacionais de Saúde Mental (CNSM) ${ }^{2}$, os quais, minimamente, desde o princípio, se inseriram as questões que se referiam à demanda materno-infantil, ao atendimento a sujeitos com diagnóstico de transtorno mental como um todo e ao atendimento, em nível escolar, às crianças com algum tipo de comprometimento físico, sensorial ou mental.

A partir dos relatórios produzidos com a realização das CNS pôde-se vislumbrar um panorama histórico mais fiel com relação à lógica proposta para atendimento das demandas em saúde mental infantil, ou o vácuo existente quanto à problematização e, consequentemente, à efetivação de ações que contemplem o seguimento.

\section{Método}

A criação de um corpus de pesquisa ocupou um lugar privilegiado na perspectiva metodológica de Análise do Discurso (AD) de base foucaultiana, na medida em que consistiu na escolha e construção de um processo discursivo representativo de um dado tempo e espaço e de uma noção ideológica: as CNS. Os documentos levantados foram analisados a partir de suas referências históricas, políticas e econômicas, resgatando-se o momento histórico/situacional de cada evento e sua expressão no produto de cada relatório.

Considerando-se, que publicações literárias, científicas e documentais são frutos de traduções da realidade, que alicerçam verdades e 
constroem cotidianos, assumiu-se, no presente trabalho, a importância de resgatar a história das políticas para a saúde mental infantil a partir dos relatórios das CNS, na tentativa compreender em que ponto se situa quando se fala dessas políticas em pleno século XXI.

Sendo assim, nos meses de abril e junho do ano de 2012, em pesquisa a fontes virtuais de documentos, foram resgatados os relatórios e/ou atas disponibilizados pelo Ministério da Saúde em seu acervo. Até o momento da pesquisa registrou-se a ocorrência de quatorze (14) CNS.

Paralelamente, foi consultada também a literatura científica especializada em saúde mental que resgata os registros históricos existentes na relação de obras médicas e médico-pedagógicas da época. Por médica leia-se psiquiátrica. Diversos foram os médicos psiquiatras que no início do século $X X$ fundaram instituições ou serviços anexos a hospitais psiquiátricos, com o objetivo de dar assistência à demanda infanto-juvenil.

De todas as CNS, realizadas desde 1941 , apenas a $2^{\mathrm{a}}$ não apresentou documento disponível para acesso virtual ou impresso, cuja razão dessa lacuna é desconhecida pelo Ministério da Saúde.

As CNS, que, conforme acima, até 2014 totalizavam quatorze (14) eventos, foram instituídas no transcorrer da primeira administração do governo de Getúlio Vargas, através da Lei n. 378, de 13/01/1937, com previsão de realização a cada dois (2) anos.

\section{Resultados/Discussão}

Os anos que antecedem a realização das CNS, embora de forma incipiente, descoordenada e não uníssonas criaram mecanismos de respostas às demandas para a área da saúde e da saúde mental de crianças e adolescentes.

A virada do século $X X$ e os acontecimentos políticos, econômicos e sociais ocorridos no Brasil, dentre eles o início da urbanização nas capitais e em destaque a efetivação do Brasil enquanto República, reverberou também nas ações dirigidas para o amparo à criança. $O$ protagonismo das ações religiosas sobre as demandas sociais sai de cena para dar lugar à tentativa de construção de um Estado Laico, resguardado pela doutrina científica. Todos os intentos com foco na mudança tinham o objetivo de efetivar o estabelecimento do Brasil enquanto nação civilizada nos moldes europeus.

Após anos de dependência dos recursos filantrópicos para manter ativas políticas no campo principalmente da saúde e educação, o primeiro governo de Getúlio Vargas assumiu o compromisso de implicação do Estado como agente implementador de políticas sociais. 
As políticas voltadas para a saúde da criança destacaram-se nesse período (Fonseca, 1993; Monarcha, 2009).

Buscando fortalecer o patriotismo e o estímulo ao desenvolvimento da nação o governo varguista apontou sua mira para a infância e a adolescência. No paradigma de crescimento tinha-se como meio o trabalho e como instrumento a mão de obra dos futuros cidadãos. Assim, aprovou medidas e apoiou a fundação de instituições que objetivassem tanto a assistência à criança brasileira quanto 0 controle e a correção do menor em situação de vulnerabilidade, nesse período classificada como delinquente. Tudo isso com a proposta de assegurar o desenvolvimento físico e intelectual dos principais instrumentos que garantiriam o êxito da nação.

A medicina legal foi o grande trunfo desse governo para efetivar os planos de controle da infância. Associando políticas de caráter assistencial e de repressão, a medicina legal articulou seus conhecimentos a modelos pedagógicos e psicológicos emergentes, tudo isso amparado pela prerrogativa eugênica da profilaxia criminal (Fonseca, 1993; Silva, 2003). Foi nesse contexto que Getúlio Vargas pensou as CNS.

Inicialmente, essas Conferências estiveram vinculadas aos Ministérios da Educação e da Saúde ${ }^{3}$, tendo como participantes, exclusivamente, agentes intergovernamentais (autoridades dos Estados e do Território do Acre), não havendo espaço para os movimentos coletivos vinculados à opinião pública. Todavia, apesar de instituídas em 1937, somente em 1941 as Conferências foram oficialmente convocadas.

Embora sob a égide do mesmo Ministério, as ações e responsabilidades eram demandas de acordo com as especificidades das áreas. Para a educação, buscava-se realizar um diagnóstico situacional em âmbito nacional, propondo-se a revisar e traçar metas de organização do sistema nacional de ensino até então vigente. Os ensinos primário, normal e profissional tiveram uma especial atenção, assim como o "problema da proteção da criança 4" (Ministério de Educação e Saúde, 1941, p. 36). Para a saúde, as metas tinham foco principal na medicina preventiva e nas ações sanitárias sobre doenças como malária, tuberculose, lepra e doenças venéreas. Mapear as ações assistenciais em saúde desenvolvidas até então, também foi um dos principais objetivos da $1^{\text {a }}$ CNS.

As duas conferências tiveram o mesmo olhar exploratório sobre 0 cenário tanto educacional quanto de saúde do Brasil, com a função de ordenar e buscar compreender como o país havia organizado até então esses dois eixos. Como panoramas de ação, a infância e a adolescência inseriram-se em ambas as linhas. Criou-se o Departamento Nacional da Criança, que estava submetido ao Ministério da Educação e Saúde e que esteve presente nas duas conferências, sendo um dos relatores gerais da $1^{\text {a }}$ CNS. Além disso, a 
proteção à maternidade, à infância e à adolescência foi declarada como um dos objetivos gerais do processo como um todo.

Não houve nenhum registro específico que tratasse diretamente sobre ações ou propostas para saúde mental infanto-juvenil. Entretanto, a $1^{\text {a }}$ CNE já sinalizava, mesmo que de forma ainda rudimentar, para a existência dessa questão. No questionário sobre a situação educacional e cultural dos Estados, no item referente ao ensino primário encontra-se o subitem "ensino para excepcionais" (Ministério de Educação e Saúde, 1941, p. 24). A pergunta que se fez foi: "70. Existem, no Estado, estabelecimentos de ensino para excepcionais, tais como escolas para cegos, surdos-mudos, débeis mentais, débeis físicos? Por quem são mantidos esses estabelecimentos?" (Ministério de Educação e Saúde, 1941, p. 24).

A proposta de realização de conferências em torno dos temas saúde e educação trouxe consigo a busca pela organização de duas políticas sociais essenciais para o desenvolvimento da nova república, como abordado anteriormente. No que tange ao tema da saúde mental, diversas ações e serviços já existiam no Brasil quando da primeira conferência, todavia sua existência e sistematização ocorriam sem uma organização enquanto políticas públicas. O surgimento de tais serviços estava ligado ao clamor social por ordem e pela chamada proteção e organização da juventude brasileira.

Apesar da exigência legal para que ocorressem a cada dois anos, somente nove anos após a realização da primeira CNS, promoveu-se a realização da $2^{a}$ CNS, em 1950, durante o governo do presidente Eurico Gaspar Dutra. Ainda sob a responsabilidade do Ministério da Saúde e Educação, a $2^{a}$ CNS teve como objetivo central pensar as questões sanitárias do Brasil, apresentando como temas adjacentes: malária; segurança do trabalho; condições de prestação de assistência médica sanitária e preventiva para trabalhadores e gestantes.

A $2^{a}$ CNS não apresenta registro oficial como relatórios ou atas de reunião. Todavia, embora haja essa lacuna documental, importantes acontecimentos ocorreram em decorrência, direta ou indireta, desse evento, como a criação do Ministério da Saúde ao se separar o Ministério de Educação e Saúde.

Transcorridos treze anos desde a $2^{a}$ CNS, realizou-se a $3^{a}$ CNS. Convocada pelo então presidente da república, João Goulart, essa conferência apresentou um forte caráter avaliativo quanto ao cenário da saúde pública que se desenhava até então. As questões sanitárias permaneceram como foco de discussões. A inovação se deu com a inserção do tópico "Doenças Degenerativas e Mentais", aplicado a crianças, adolescentes e adultos. Dentre a categoria de doenças mentais destacou-se as oligofrenias, tendo como subitens a debilidade mental, imbecilidade e idiotia. 
Embora nas CNS pré-existentes não houvesse nenhuma menção ao panorama da assistência à saúde mental, os dados apresentados pelo relatório da $3^{a}$ CNS evidenciam a edificação, em anos anteriores, de um grandioso complexo de assistência à saúde mental nas principais capitais do Brasil.

O embasamento que sustenta tal afirmação se dá ao realizar-se, de forma comparativa, uma análise dos dados que constam no próprio documento: para o tratamento de cânceres o país dispunha de 1.725 leitos no sistema de atendimento público; para a saúde mental havia até o momento da conferência 60.000 leitos disponíveis para tratamento, sendo a expectativa almejada de 75.000, 1 leito psiquiátrico para cada 1.000 habitantes. Esses 60.000 leitos estavam distribuídos em 173 hospitais psiquiátricos, nos quais 55 eram públicos e 118 particulares. O relator do documento destaca que a maior parte da verba que mantinha os hospitais psiquiátricos particulares era proveniente de financiamento do setor público (Ministério da Saúde, 1963).

Com relação ao perfil epidemiológico dos diagnósticos de doenças mentais, apresentado no relatório da $3^{a}$ CNS, dados sobre internações e atendimentos realizados a crianças foram inseridos no registro oficial do evento.

De acordo com o relatório, o total do número de crianças admitidas no ano de 1962 no Brasil foi de 958, o que representou 2,41\% dos atendimentos ocorridos em saúde mental no período, sendo 954 de nascidas no Brasil e 4 nascidas em países estrangeiros. Desses atendimentos, $54 \%(1,3 \%$ do total de atendimentos $)$ eram de crianças do sexo masculino e $46 \%(1,1 \%$ do total de atendimentos) do sexo feminino.

De acordo com a nosologia estabelecida no relatório supracitado, a primeira categoria apresentada, que correspondeu às psicoses por infecções e por infestações correspondeu a 5,5\% dos casos atendidos; a categoria psicoses devidas à sífilis correspondeu a $0,52 \%$; os diagnósticos de psicoses exotóxicos representaram $1,15 \%$; a categoria "psicoses endotóxicas" também representara $1,15 \%$ das admissões; as psicoses por lesões cerebrais corresponderam a 1,31\%; as oligofrenias a 36,3\%; as epilepsias a $18,7 \%$ das crianças atendidas; as esquizofrenias a $12 \%$; as psicoses maníaco-depressivas representaram $3 \%$ das admissões; as psicopatias mistas e associadas a $0,52 \%$; as psicoses psicogênicas, $3,13 \%$; as neuroses, $4,2 \%$; as personalidades psicopáticas, $5,74 \%$ dos atendimentos. Os estados mentais não classificados representaram $5,74 \%$ dos atendimentos e os sujeitos avaliados como sem perturbações metais totalizaram $1,04 \%$ das admissões.

Avaliando-se os dados expostos, entre os diagnósticos mais frequentes teve-se em primeiro lugar a categoria Oligofrenia, com 348 casos (36,3\%); em seguida, as Epilepsias, com 179 casos 
$(18,7 \%)$, e a Esquizofrenia, com 115 casos, ou seja, 12\% da população de crianças atendidas.

A principal característica do processo diagnóstico desse período era a busca por evidências fisiológicas que o sustentassem. Os médicos psiquiatras procuravam estabelecer paralelos entre evidências comportamentais e fatores anátomo-fisiológicos (Assumpção, 1995). Nesse sentido, o referencial nosológico das doenças psiquiátricas era o adulto. Os trabalhos em psiquiatria infantil datados do início do século XX, no Brasil, tinham como base a lógica "adultomorfa" de nosologia (Assumpção, 1995, p. 27). Consequentemente, as medidas de intervenção também seguiam o referencial das medidas aplicadas em adultos.

Quatro anos após a execução da $3^{a}$ CNS, dá-se início a $4^{a}$ CNS - que abordou o tema "Recursos humanos para as atividades de saúde" realizada em 1967 na cidade do Rio de Janeiro.

Primeira das quatro conferências realizadas durante o período do regime militar, a $4^{a}$ CNS promoveu debates e mesas redondas com profissionais especialistas em saúde pública e autoridades do Ministério da Saúde, além de proporcionar espaço para a abertura de relatos de experiências de outros dois países da América Latina, sendo eles Venezuela e Colômbia. Contou também com a presença de um painel internacional da Organização Pan-americana de Saúde (OPAS).

Atrelando a noção de saúde ao desenvolvimento econômico, o relatório do evento ressaltou a ideia de que a promoção de saúde está diretamente relacionada com o crescimento econômico do Brasil sob o discurso de que "(...) saúde é riqueza (...)" (Ministério da Saúde, 1967, p. 46). Refletir sobre as práticas profissionais realizadas nos serviços de saúde inscreve-se na agenda nacional e internacional de desenvolvimento das nações, na medida em que essa também se configura como uma demanda da Organização Mundial da Saúde (OMS) no período, como destaca o relatório da referida Conferência.

O evento problematizou também a perspectiva curativa que sustentava as práticas em saúde, principalmente as ações orientadas pelos médicos. No dizer do relator, as escolas médicas existentes naquele período trabalhavam com a formação do profissional médico destinado estritamente a curar, em detrimento da defesa e preservação da saúde (Ministério da Saúde, 1967).

No que diz respeito à saúde da criança e do adolescente, mais precisamente ao campo da saúde mental desse grupo, não houve relato sobre o tema em específico, apenas a confirmação da onipresença do tema numa abordagem global na agenda nacional de saúde.

O método de seminários introduzido pela $4^{a}$ CNS foi reeditado na $5^{a}$ CNS. 
Realizada em agosto de 1975, em Brasília, a 5 a CNS, convocada em obediência ao Decreto n. 52.301, de 27/07/1963, promoveu o debate de cinco (5) temas em quatorze (14) grupos de trabalhos, com no máximo 15 participantes cada grupo. Os temas abordavam, respectivamente: Sistema Nacional de Saúde; Programa de Saúde Materno-Infantil; Sistema Nacional de Vigilância Epidemiológica; Programa de Controle das Grandes Endemias; Programa de Extensões das Ações de Saúde às Populações Rurais.

Outro tema problematizado, ou minimamente citado pelos relatórios das conferências anteriores é o tema da saúde materno-infantil. De acordo com o relatório da $5^{a}$ CNS, essa questão foi levada para discussão em função de trazer, em seu núcleo, o foco na parcela até então mais vulnerável da população. Quando da realização do evento, a população materno-infantil correspondia a $70,98 \%$ da população total, contabilizando, aproximadamente, 76.170 .700 sujeitos (Ministério da Saúde, 1975, p. 28).

Por categoria materno-infantil compreendia-se mulheres entre 15 e 49 anos, crianças entre zero e 15 anos e adolescentes do sexo masculino com idades entre 15 e 19 anos. Em virtude da abrangência, essa categoria representava, aproximadamente, $71 \%$ do total da população brasileira da época, cujas características de vulnerabilidade eram marcadas pelas deficitárias condições econômicas e sociais, apresentando elevados níveis de morbidade e mortalidade (Demo, 1981).

As principais afecções, como se constata no documento da $5^{a}$ CNS, eram expressões das frágeis condições de vida da população, sendo, desta feita, evitáveis.

O tema da saúde materno-infantil foi retomado a partir da discussão do Sistema Nacional de Vigilância Epidemiológica. Segundo o documento, as doenças transmissíveis caracterizavam-se como uma das principais causas de óbito da população infantil, seguidas pelas supracitadas gastrenterites e doenças respiratórias (Ministério da Saúde, 1975, p. 28). Fatores ligados às condições socioeconômicas de vida são decisivos para configurar esse panorama epidemiológico da época.

A saúde mental, tema geral do evento, e a saúde mental infantojuvenil, não constam nas discussões apresentadas pelo relatório da $5^{\text {a }}$ CNS.

De forma concisa, a $6^{a}$ CNS retomou diversos pontos de discussão abordados pela Conferência que a precedeu, ambas realizadas durante o governo do General Ernesto Geisel. De forma geral, o texto manteve a reflexão em torno da reestruturação e organização do sistema de saúde do país. Mais sucintos, os relatores reproduziram a crítica anterior ao sistema centralizador de planejamento de ações na esfera federal e na perspectiva curativa e individual da assistência em saúde. 
Nesse evento o tema da saúde materno-infantil foi preterido e a questão da saúde mental permaneceu ausente. O documento cita a realização de uma conferência proferida pelo Doutor Josicelli Freitas com o título: "Diretrizes Programáticas de Saúde Mental". Essa conferência, entretanto, não foi inserida no documento oficial, sendo o seu conteúdo desconhecido para o leitor.

Em sequência, a 7a CNS, realizada em março de 1980, em Brasília, durante o governo do militar João Baptista de Oliveira Figueiredo, ampliou a discussão que abordava a revisão do sistema de saúde implantado no Brasil. A última das quatro conferências realizadas durante o período do Regime Militar propõe-se, através do tema "A extensão das ações de saúde através dos serviços básicos", a refletir sobre as práticas em saúde, até então destinadas ao cidadão brasileiro contribuinte da Previdência Social, ampliando as ações para uma maior gama de extratos da sociedade, quais sejam, zonas rurais, Regiões Norte e Nordeste, periferias das grandes cidades.

A proposta era formular e implantar o Programa Nacional de Serviços Básicos de Saúde (PREV-SAÚDE), universalizando o acesso a esses serviços, como programas de vacinação, combate a epidemias e endemias, dentre outros. O que antes era uma semente passa a tomar a forma de uma nova política em saúde para o Brasil.

Se comparado aos textos das conferências anteriores, a $7^{a}$ CNS apresentou um cunho mais político, indicando a preocupação com a preparação para o processo de redemocratização do país, expondo diversas críticas, principalmente, ao modelo de saúde sedimentado durante o Regime Militar, como foi o caso do investimento em tecnologias de alto custo, e na criação de leitos hospitalares em detrimento do investimento em obras de saneamento, tratamento da água, programas de enfrentamento de epidemias e endemias.

Como desafio, o evento buscou problematizar o que convencionou chamar de "Indústria da Doença" (Ministério da Saúde, 1980, p. 21), fortalecida na primeira década do Regime Militar. Os vultosos recursos destinados à saúde eram empregados, em sua grande maioria, à manutenção de serviços e insumos sofisticados e especializados no setor tratamento/recuperação dos trabalhadores, contribuintes da previdência social (Ministério da Saúde, 1980). O mercado da saúde tinha como engrenagem principal a doença, centrada na assistência privada que, por sua vez, era financiada com recursos públicos. Essa prática preteriu o investimento nas reais necessidades da população, contribuindo para o aumento das desigualdades sociais (Ministério da Saúde, 1980).

Esse quadro social criado pela ausência do Estado nas políticas de assistência à população gerou (principalmente nas áreas da saúde e educação), no final da década de 1970 e início da década de 1980, uma comoção social em busca da mudança de cenário. Aliado a isso, 
havia também o clamor pelo fim da ditadura militar e retorno da democracia.

Dentre esses movimentos de reivindicação política e social um destacou-se no campo da saúde, o Movimento da Reforma Sanitária. Composto principalmente por intelectuais críticos do sistema de saúde e ávidos pela retomada da democracia, o movimento teve início ainda na década de 1960. Abafado pela repressão militar, apenas no fim da década de 1970 toma novo fôlego.

Em 1979 membros do Movimento da Reforma Sanitária organizaram - 10 Simpósio Nacional de Política de Saúde - um ano antes da realização da 7a CNS e paralelamente às conferências -, marco para o movimento sanitarista.

A postura política assumida pela categoria dos sanitaristas destacouse nesse momento da história do Brasil, criando, paralelo à realidade do sistema de saúde vigente, uma postura contra-hegemônica que contribuiu sobremaneira com a reforma da saúde. Unidos a movimentos populares, aos trabalhadores em saúde e aos sindicatos,

(...) o movimento sanitarista conseguiu, aproveitando-se de contradições existentes em nível do próprio aparelho estatal e de sua grande capacidade de iniciativa para criar foros autônomos de discussão e de elaboração de políticas, articular projetos de reorganização dos serviços e das práticas sanitárias. Propostas estas que transcendiam o tradicional campo da Saúde Pública e diziam respeito aos mecanismos de financiamento, compra e de produção de serviços de saúde de todo o sistema, até mesmo do setor privado; enfim elaboravam, paulatinamente, novas orientações de política de saúde (Campos, 2006, p. 95-96).

O Movimento da Reforma Sanitária teve grande impacto nas Conferências de Saúde que o sucedem, norteando toda a reformulação da saúde brasileira iniciada na década de 1980 .

Em síntese, o sistema de saúde brasileiro passava por significativas mudanças. O projeto sugerido e materializado na proposta do PREVSAÚDE era a descentralização das ações em três níveis: primário, secundário e terciário. O primário dizia respeito às atividades realizadas nas comunidades com o objetivo de promover saúde e evitar ou de dar resolutividade a casos de epidemias e endemias. 0 nível secundário era responsável pelo processo diagnóstico e tratamento do enfermo e o terciário pela recuperação/reabilitação de sujeitos acometidos por doenças crônicas.

A Saúde Mental ganha espaço nesse cenário, incluindo-se explicitamente a categoria materno-infantil. A atenção em saúde mental como um todo foi dividida pelo relatório em três níveis: Prevenção primária; Prevenção secundária; Prevenção terciária. 
O domínio do saber médico sob as práticas em saúde mental foi expressamente apresentado no texto da $7^{a}$ CNS, repudiando qualquer outro saber (psicológico, sociológico, antropológico, filosófico etc.) que não o médico, nas questões de resolução clínica em saúde mental.

O documento apresenta os principais diagnósticos, baseado na Classificação Internacional de Doenças (CID), edição de 1975. São eles: Personalidades Neuróticas; Personalidades Psicopáticas; Alcoolismo e Dependência de Drogas; Oligofrenias (Deficiência Mental); Epilepsias; Psicoses Orgânicas Agudas; Psicoses Orgânicas Crônicas (Demência); Psicoses Afetivas; Psicoses Esquizofrênicas.

Em cada categoria nosológica apresentada segue uma breve definição, a forma de prevenção e a forma de tratamento. Para a faixa infantil são identificadas duas categorias nosológicas, a oligofrenia e as epilepsias, tradicionalmente destinadas a esse grupo, como visto anteriormente. Esses diagnósticos são atrelados à saúde da mãe durante o processo gestacional.

Ademais, ficaram reservadas em nível primário, ou seja, nos postos e centros de saúde, ações de prevenção a transtornos mentais na infância, atrelados também à saúde da parturiente, da mãe e da família.

Durante a presidência de José Sarney, em 1986, realizou-se em Brasília a $8^{a}$ CNS. Com a duração de três dias, o evento trouxe como temas de debate: (I) Saúde como Direito; (II) Reformulação do Sistema Nacional de Saúde; (III) Financiamento Setorial.

De forma geral, a $8^{a}$ Conferência somou-se aos diversos elementos que deram corpo a importantes mudanças, principalmente políticas, no Brasil. No bojo da redemocratização, os direitos sociais passaram a ser foco de reflexões e de intervenções mais efetivas. A presidência de Sergio Arouca na comissão organizadora do evento, nome de destaque no Movimento da Reforma Sanitária, evidencia esse desejo de realizar efetivamente a mudança, aqui especificamente no campo da saúde pública.

A $8^{a}$ CNS problematiza o panorama da saúde pública brasileira, e como esta até então havia se organizado, intencionando não mais abordar a reforma administrativa e financeira, assuntos discutidos na grande maioria das conferências nacionais de saúde realizadas anteriormente, mas fazendo emergir a proposta de reformulação profunda do sistema de saúde brasileiro.

Com o Movimento da Reforma Sanitária o tópico "saúde/doença" foi levantado sob uma perspectiva macropolítica, transcendendo a lógica do setor ao buscar na sociedade suas referências, ao invés de parâmetros de saúde estabelecidos globalmente. Além disso, lutou-se pela universalização do direito à assistência à saúde, enxergando esse constructo como fator atravessado por condições econômicas, sociais, culturais e políticas. 
Para promover essa mudança foi revista a legislação responsável por delimitar os conceitos de promoção, proteção e recuperação da saúde (Ministério da Saúde, 1986).

As discussões prepararam o terreno para a implantação do Sistema Único de Saúde (SUS). As principais demandas foram expostas com a expectativa de que fossem inseridos no texto final da Carta Constitucional de 1988. Sendo assim, as matérias mais específicas sobre saúde (saúde básica, saúde mental, saúde materno-infantil, saúde do idoso e etc.) foram abordadas no evento seguinte.

A 9a CNS ocorre seis anos depois, em 1992. Todavia, nesse intervalo, importantes iniciativas foram tomadas para a efetiva mudança do cenário sociopolítico brasileiro.

Em 1988, o Brasil aprova a nova Carta Constitucional. Dentre os principais destaques têm-se a universalização dos direitos sociais, ampliando a condição de cidadania ao incluir concretamente a infância, a adolescência, o idoso, o deficiente, dentre outras, enquanto categorias portadoras de direitos constitucionais. A promulgação da nova Carta Magna instaura, assim, a legalidade e o estímulo, por parte do Estado, às ações organizadas em prol das mudanças relacionadas a essas categorias.

Em 19 de setembro de 1990, aprovou-se a Lei Orgânica da Saúde, Lei No 8.080, que "dispõe sobre as condições para a promoção, proteção e recuperação da saúde, a organização e o funcionamento dos serviços correspondentes e dá outras providências" (Lei nº. $8.080,1990)$. E em 28 de novembro de 1990, aprovou-se a Lei No 8.142, que "dispõe sobre a participação da comunidade na gestão do sistema único de saúde (SUS) e sobre as transferências intergovernamentais de recursos financeiros na área da saúde e dá outras providências" (Brasil, 1990). Além disso, a Lei No 8.142/90 estabelece a realização de conferências prévias às nacionais nas diferentes esferas de governo, prevendo a realização a cada quatro (4) anos de tais eventos, a serem organizados pelos conselhos de saúde.

A $8^{a}$ CNS semeou os avanços colhidos com a implantação do Sistema Único de Saúde (SUS) na década de 1990. Como consequência, a 9a CNS dá seguimento às mudanças e às inquietudes, agora em um novo Estado Democrático.

Com o tema "Municipalização é o Caminho", a 9a conferência foi a primeira a contar com debates prévios ocorridos nas etapas estaduais e municipais, demonstrando a efetiva articulação do grupo do movimento em favor da Reforma sanitária.

Para o campo da saúde mental sustentou-se a implantação da Reforma Psiquiátrica, aprovando a progressiva extinção do aparato manicomial e a implementação de políticas que substituíssem os serviços asilares. 
Paralelamente ao cenário de transformação na saúde ocorriam também relevantes mudanças em outras áreas sociais, as quais inseriram outros grupos sociais no centro das discussões políticas. Ainda em 1990, mais precisamente em 13 de julho, foi sancionada a Lei No 8.069, que institui o Estatuto da Criança e do Adolescente (ECA).

Com o advento do ECA inaugura-se oficialmente, no Brasil, a Doutrina da Proteção Integral à criança e ao adolescente. Contrariamente ao percurso histórico da nação, marcado pela tradição do não-direito (Pinheiro, 2006), o Estatuto efetiva a condição da criança e do adolescente enquanto sujeitos de direito.

Embora realizada dois (2) anos após a sanção do ECA a ga CNS articulou, ainda que de forma incipiente, os eixos saúde mental/infância e adolescência. Apesar disso, abriu importante precedente para o aprofundamento deste eixo na $2^{a}$ Conferência Nacional de Saúde Mental, realizada também em dezembro de 1992, dois meses depois do encerramento da 9a CNS.

Em 1996, quando da $10^{a}$ CNS, cita-se, pela primeira vez, de forma direta, o Estatuto da Criança e do Adolescente. A finalidade era de concretizar a implantação das novas leis em saúde, assistência social e infância e juventude.

10.2 Defender que o Ministério Público seja o tutor da legislação em saúde, da Assistência Social e do Estatuto da Criança e do Adolescente, fiscalizando sua implantação e sua execução nos setores público e privado, e tomando as providências cabíveis no caso de descumprimento do texto legal (Ministério da Saúde, 1996, p. 12).

A saúde da criança, enquanto temática, partia da noção de saúde como direito, devendo ser garantido e fiscalizado seu cumprimento. Para isso, o documento levantou a necessidade de utilização das Varas da Infância e Juventude e dos Conselhos Tutelares como atores reguladores legais desta fiscalização. Pela primeira vez também se cita e demandam-se responsabilidades das supracitadas instituições. O foco principal do eixo de discussão "Saúde Mental" girou em torno da proposta da Reforma Psiquiátrica de substituição progressiva do modelo asilar pelos Serviços de Atenção Integral à Saúde Mental. A expectativa era que essa mudança ocorresse até o ano 2000, sendo apoiada pela aprovação do projeto de lei do Deputado Paulo Delgado 5 .

As discussões específicas no campo da Saúde Mental foram levantadas nas Conferências Nacionais de Saúde Mental. Sendo assim, os temas saúde mental/infância e juventude não são pontuados diretamente nem na $10^{a}$ CNS nem no então Projeto de Lei Paulo Delgado. 
Quatro anos mais tarde, em 2000, ainda sob a presidência nacional de Fernando Henrique Cardoso, ocorre a $11^{\text {a }}$ CNS. A efetivação do Sistema Único de Saúde ainda se apresentava como o foco das discussões. O desafio do acesso, da qualidade do serviço prestado e da humanização da assistência a partir da noção de controle social tematizaram o evento.

A $11^{a}$ Conferência deu continuidade às elaborações e reflexões levantadas nos eventos que sucederam a $8^{a}$ CNS, marco de mudança para a Reforma Sanitária brasileira.

Precisamente com relação à Reforma Psiquiátrica os anseios permaneceram os mesmos. A expectativa de abolição do aparato manicomial estabelecida na $10^{a}$ CNS não se efetivou. O Projeto de Lei Paulo Delgado somente se tornou concretamente lei em 2001. Apesar disso, a necessidade de criação de uma política de saúde mental para - grupo infanto-juvenil foi destacada no relatório final da $11^{a}$ Conferência Nacional de Saúde (Ministério da Saúde, 2001).

Por decisão do Plenário do Conselho Nacional de Saúde e desobedecendo ao decreto $n^{\circ}$ 9.872, de 05/05/90, a 12a CNS realizou-se um ano antes do previsto, ou seja, em 2003. Essa alteração se deu em meio a novas mudanças políticas pelas quais passava o país. A eleição do candidato do Partido dos Trabalhadores, Luís Inácio Lula da Silva, para presidente do Brasil promoveu uma reviravolta histórica no quadro político nacional.

Essa antecipação intencionou dar continuidade à revisão dos 15 anos do Sistema Único de Saúde, buscando vislumbrar prospectivamente os rumos a serem tomados.

Para a saúde mental infanto-juvenil assinalou-se a necessidade de realização de Conferências Nacionais da Criança e do Adolescente, destacando atenção especial à questão da saúde mental, e à criação do Centro de Assistência Psicossocial para a Infância e Adolescência, o CAPSi (Ministério da Saúde, 2004).

A $13^{a}$ CNS mantém a perspectiva de discussão da saúde mental pela via da Reforma Psiquiátrica, buscando articular as ações com outros serviços, formando uma complexa e dinâmica rede de atenção em saúde.

Com relação à saúde mental de crianças e adolescentes, as políticas de inclusão social e de garantia de direitos ampliam o foco de proposição da questão, no qual ações desportivas, culturais e de lazer são apresentadas como possíveis na articulação da problemática, principalmente no que se refere ao consumo de álcool e drogas por essa faixa etária, assim como para adultos e idosos.

A estratégia de inserção dos serviços de atenção básica de saúde no atendimento e intervenção à demanda de saúde mental para a criança e o adolescente, com destaque para a inclusão da família no processo de intervenção, também aparece nos debates, assim como sua articulação com os serviços de garantia de direitos como os 
Conselhos Tutelares e as Varas da Infância e Juventude e com as secretarias de Educação e Assistência Social (Ministério da Saúde, 2007).

Em 2011, ano da $14^{a}$ CNS, observaram-se, nos pontos documentados pelo relatório, direcionamentos e diretrizes mais objetivas para a área da saúde mental. O encontro considerou fazer cumprir a lei 10216/01, ou seja, a nova estrutura de assistência em saúde mental. Com relação ao serviço de atendimento CAPSi, o relator destacou o objetivo central da assistência:

Garantir a implantação do CAPS para a infância e adolescência (CAPSi) para facilitar o controle das medicações indicadas às crianças comprometidas psiquicamente, portadoras de autismo, psicoses, neuroses graves e todos aqueles que, por sua condição psíquica, estão impossibilitados de manter ou estabelecer laços sociais (Ministério da Saúde, 2012, p. 57).

\section{Considerações finais}

Apesar de secular, no Brasil, é apenas com a inauguração do Hospício Dom Pedro II, no Rio de Janeiro, em 1852, que se instaura a assistência psiquiátrica institucional, proliferando-se rapidamente pelo país.

Desta feita, o modelo assistencial em saúde mental no Brasil caracterizou-se por ações voltadas para a assistência médico-legal de caráter asilar, e nitidamente focado na assistência ao adulto diagnosticado com algum tipo de transtorno mental. Por sua vez, os manicômios materializam a proposta de segregação e isolamento dos sujeitos diagnosticados como doentes mentais.

Todavia, a segunda metade do século XX marcou uma reviravolta no modelo de assistência à loucura descrito acima. Esse modelo de assistência, apoiado em outros movimentos mundiais, a partir da década de 1960, passou a incorporar às suas práticas o exemplo europeu classificado como "psiquiatria preventiva e comunitária", com vistas à humanização de hospitais. Foi somente a partir da segunda metade da década de 1970 que se iniciou o movimento de reforma psiquiátrica no Brasil, e apenas no fim dos anos 1980 incorporou-se a esse movimento a noção basagliana de desinstitucionalização (Borges \& Baptista, 2008).

A reforma psiquiátrica ocorrida em território brasileiro é a expressão pública do descontentamento da sociedade com o modelo até então utilizado para atender as demandas em saúde mental, o qual tinha a instituição do manicômio como lócus privilegiado de atuação, em ações que atendiam a perspectiva de tratamento curativo, segundo parâmetros de normalidade historicamente estabelecidos. A proposta 
central de tal reforma foi o redirecionamento das antigas práticas manicomiais para serviços de caráter substitutivo. Um marco emblemático foi a apresentação do Projeto de Lei $n^{\circ}$. 3.657/89, pelo Deputado Paulo Delgado, a qual versava "sobre a extinção progressiva dos manicômios e sua substituição por outros recursos assistenciais e regulamentava a internação psiquiátrica compulsória" (Borges \& Baptista, 2008, p. 457).

Com a promulgação da Constituição Federal de 1988, tais serviços passaram a ser incorporados aos serviços de saúde pública inseridos no âmbito do Sistema único de Saúde, com seu arcabouço legal estabelecido pelas Leis no 8.080/90 e no 8.142/90.

Contudo, nesse novo panorama em que se estabeleceu a saúde pública, e mais especificamente a saúde mental brasileira, a questão da política de saúde mental para crianças e adolescentes não se apresentou como tema específico.

Abordar o tema da saúde mental para a infância e juventude no Brasil implica a retomada de diferentes momentos históricos pelo qual passou a nação, agregando os aportes culturais, econômicos e políticos referentes a esses distintos períodos. Este trabalho objetivou apenas realizar um estudo historiográfico resumido, em que o resgate histórico se fez necessário.

Ao admitir o caráter de construção histórica, assume-se, como consequência, seu caráter de produção subjetiva. Não apenas a escola e a família, mas, também, a ciência psiquiátrica, contribuíram sobremaneira para a construção da infância moderna, bem como, em larga escala, para a generalização do poder psiquiátrico. Assim, a sociedade moderna forjou a infância normal e a infância anormal.

As CNS ocorridas no Brasil desde a década de 1940 enquanto política de Estado, até os dias atuais, apresentam importantes registros de como a saúde, e a saúde mental, têm sido tratadas. Elas registraram pequenos fragmentos da grande lacuna existente sobre as políticas de saúde mental para a infância e abriram precedente para a realização das CNSM, estas sim, eventos politicamente mais consistentes e cujas propostas sugeriam a mudança do status quo, apoiando e sustentando a efetivação dos Centros de Assistência para a Infância e Adolescência (CAPSi).

Para a infância e juventude esses eventos dão pistas de como foi sendo construído o que hoje conhecemos como assistência em saúde mental para esse grupo social. Resgatá-los promove um movimento de análise crítica do processo, bem como de espaços para a proposição de mudanças positivas. 


\section{Referências}

Ariès, P. (1978). História social da criança e da família. Rio de Janeiro: LTC.

Assumpção Jr., F. B. (1995). Psiquiatria infantil brasileira: Um esboço histórico. São Paulo: Lemos.

Borges, C. F., \& Baptista, T. W. F. (2008). O modelo assistencial em saúde mental no Brasil: a trajetória da construção política de 1990 a 2004. Caderno Saúde Pública, 24(2), 456-468.

Campos, G. W. S. (2006). A saúde pública e a defesa da vida. (3a Ed.). São Paulo: HUCITEC.

Couto, M. C. V., \& Delgado, P. G. G (2015). Crianças e adolescentes na agenda política da saúde mental brasileira: inclusão tardia, desafios atuais. Revista Psicologia Clínica, 27(1), 17-40.

Demo, P. (1981). Política social nas décadas de 60 e 70. Fortaleza: UFC.

Fonseca, C. M. O. (1993). A saúde da criança na política social do primeiro governo Vargas. PHYSIS - Revista de Saúde Coletiva, $3(2), 97-116$.

Lei no. 8.080 (1990, 19 de setembro). Dispõe sobre a organização do Sistema Único de Saúde (SUS) e dá outras providências. Brasília, DF: Diário Oficial da União.

Ministério de Educação e Saúde (1941). Relatório da $1^{a}$ Conferência Nacional de Educação e $1^{a}$ Conferência Nacional de Saúde. Brasília: Autor.

Ministério da Saúde (1963). Relatório da $3^{a}$ Conferência Nacional de Saúde. Brasília: Autor.

Ministério da Saúde (1967). 4a Conferência Nacional de Saúde, recursos humanos para as atividades de Saúde. Brasília: Autor.

Ministério da Saúde (1975). $5^{a}$ Conferência Nacional de Saúde, relatório final. Brasília: Autor.

Ministério da Saúde (1980). 7a Conferência Nacional de Saúde, relatório final. Brasília: Autor.

Ministério da Saúde (1986). $8^{a}$ Conferência Nacional de Saúde, relatório final. Brasília: Autor.

Ministério da Saúde (1996). Relatório final da 10a Conferência Nacional de Saúde. Brasília: Autor.

Ministério da Saúde (2001). 11 a Conferência Nacional de Saúde, Brasília 15 a 19 de dezembro de 2000: o Brasil falando como quer ser tratado: efetivando o SUS: acesso, qualidade $e$ humanização na atenção à saúde com controle social: relatório final. Brasília: Autor.

Ministério da Saúde (2004). 12a Conferência Nacional de Saúde: Conferência Sergio Arouca: Brasília, 7 a 11 de dezembro de 2003: relatório final. Brasília: Autor. 
Ministério da Saúde (2007). Ministério da Saúde. Secretaria de Atenção à Saúde. Relatório de Gestão 2003-2006: saúde mental no SUS: acesso ao tratamento e mudança do modelo de atenção. Brasília: Autor.

Ministério da Saúde (2012). Relatório Final da 14a Conferência Nacional de Saúde Mental - Intersetorial. Brasília: Autor.

Monarcha, C. (2009). Psicoclínicas e cuidados da infância. Boletim Academia Paulista de Psicologia, 77(2), 274-284.

Rosemberg, F., \& Mariano, C. L. S. (2010). A convenção internacional sobre os direitos da criança: debates e tensões. Cadernos de pesquisa, 40(141), 693-728.

Silva, R. (2003). "Abandonados e Delinqüentes": A infância sob os cuidados da medicina e do Estado - O Laboratório de Biologia Infantil (1935-1941). Dissertação de mestrado apresentada ao curso de Pós-graduação em História das Ciências da Saúde da Casa de Oswaldo Cruz - FIOCRUZ, Rio de Janeiro, RJ.

\section{Endereço para correspondência \\ Clariana Morais Tinôco Cabral}

Universidade Federal do Rio Grande do Norte

Departamento de Psicologia - Centro de Ciências, Letras e Artes

Departamento de Psicologia, CCHLA - UFRN, Lagoa Nova, Campus Universitário, CEP 59078-970, Natal - RN, Brasil

Endereço eletrônico: clariana.morais@gmail.com

\section{Rosângela Francischini}

Universidade Federal do Rio Grande do Norte

Departamento de Psicologia - Centro de Ciências, Letras e Artes

Departamento de Psicologia, CCHLA - UFRN, Lagoa Nova, Campus Universitário, CEP 59078-970, Natal - RN, Brasil

Endereço eletrônico: rofrancischini@gmail.com

Recebido em: 12/08/2015

Reformulado em: 11/08/2016

Aceito para publicação em: 25/09/2016

\footnotetext{
Notas

${ }^{1}$ O tema das primeiras ações republicanas no Brasil é um assunto complexo. O presente trabalho não tem como objetivo resgatá-lo, todavia faz-se necessária sua contextualização temporal.

${ }^{2} \mathrm{O}$ foco do presente artigo está no trabalho de análise documental das CNS, devido ao pioneirismo da proposta. O que se busca é compreender a gênese das políticas em saúde mental para a infância vista sob o panorama das políticas nacionais de saúde. As CNSM são citadas em sua importância histórica e como uma das consequências políticas da realização das CNS.

3 Nesse período, os setores da educação e da saúde pertenciam a um mesmo Ministério, o MES, Ministério de Educação e Saúde, criado pelo Presidente Getúlio Vargas, no período da história do Brasil que ficou conhecido como Era Vargas (1930-1945).

4 O problema da proteção da criança era de responsabilidade da Diretoria de Proteção à Maternidade e à Infância (DPMI) e da Divisão de Amparo à Maternidade
} 
e à Infância (DAMI). Ambas fundadas no governo do presidente Getúlio Vargas. O DAMI foi extinto e em 1940, em substituição foi criado o Departamento Nacional da Criança (DNCr). Dentre os eixos a serem abarcados no campo da proteção estava prestar assistência à criança débil (Parada \& Medeiros, 2010).

${ }^{5}$ Representante na Câmara Federal do Partido dos Trabalhadores de Minas Gerais (PT-MG), o Deputado Federal Paulo Delgado submeteu ao Congresso Nacional, em 1989 , o projeto de lei que levou seu nome. O documento tinha como conteúdo a regulamentação da proteção e dos direitos da pessoa portadora de transtornos mentais, assim como dispunha sobre o reordenamento do modelo assistencial em saúde mental. Porém, somente em abril de 2001, a Lei Federal No 10.216 é sancionada, salientando que no decurso temporal foram realizadas importantes alterações no texto inicial.

* Doutora em Psicologia Social pela Universidade Federal do Rio Grande do Norte.

** Professora Titular na Universidade Federal do Rio Grande do Norte até 2014. Atualmente, mantém vínculo como professora colaboradora no programa de pósgraduação (mestrado e doutorado) em Psicologia da UFRN e de pesquisadora colaboradora do Centro de Investigações em Estudos da Criança, da Universidade de Minho (UMINHO), Portugal. 